ORGÂNICOS: EXPANSÃO DE MERCADO E CERTIFICAÇÃO

\author{
Daline F. S. Araújo \\ Graduada em Tecnologia em Meio Ambiente no CEFET-RN \\ daline_araujo@yahoo.com.br \\ Maria do Socorro Diógenes Paiva \\ Professora do Departamento de Recursos Naturais do CEFET-RN \\ msocorro@cefetrn.br \\ João Maria Filgueira \\ Professor do Departamento de Informática do CEFET-RN \\ jmfilgueira@yahoo.com.br
}

\title{
RESUMO
}

O presente artigo discute a expansão do mercado produtor e consumidor e a certificação dos produtos orgânicos. O mercado de produtos orgânicos tem apresentado grande crescimento nos últimos anos, conseqüência da maior procura pelos consumidores que se preocupam com alimentação saudável e com a "desentoxicação" do meio ambiente. Nos supermercados, lojas de produtos naturais e feiras-livres os orgânicos vêm tomando espaço e a atenção dos consumidores, mesmo apresentando custo mais elevado que os produtos convencionais. A pesquisa foi realizada em alguns supermercados da região metropolitana de Natal-RN procurando conhecer os consumidores orgânicos bem como a oferta destes no local. O que se observa é que a disponibilidade dos alimentos nas prateleiras dos supermercados sinaliza a decisão em optar pelos alimentos ecologicamente corretos, principalmente frutas, verduras e legumes. No entanto, a falta de um determinado produto bem como a falta de informação do consumidor e no estabelecimento ainda são fatores relevantes para o não consumo.

PALAVRAS-CHAVES: mercado produtor; consumidores; certificação; alimentos orgânicos; meio ambiente. 


\section{ORGÂNICOS: EXPANSÃO DE MERCADO E CERTIFICAÇÃO}

\section{INTRODUÇÃO}

Nas últimas três décadas, o uso indiscriminado de fertilizantes quintuplicou, o que é hoje uma das maiores preocupações nas diversas partes do mundo. Em vista disso e de estudos que comprovam a contaminação de alimentos e do meio ambiente por agrotóxicos, causando danos à saúde, cresce o número de consumidores que passam a criticar o modelo de agricultura vigente que utilizam agrotóxicos e fertilizantes químicos nas plantações.

A ampliação de mercados mais flexíveis e a facilidade maior ao acesso a informações por parte dos consumidores, têm levado à formação de um consumidor mais consciente e exigente na escolha e compra dos produtos alimentícios, fazendo surgir um novo tipo de consumidor o "consumidor orgânico".

Na análise de alguns autores a busca por qualidade em produtos agroindustriais tem mostrado, desde a década de 1990, um crescimento constante e significativo decorrente de mudanças nas preferências dos consumidores, motivadas, principalmente, por preocupações com a saúde pessoal e da família. Nesse contexto existem consumidores dispostos a pagar um pouco mais por produtos que possuam alguns atributos desejados.

Diante desta realidade, o mercado de produtos de origem orgânica vem ganhando cada vez mais espaço. É o caso das tradicionais lojas de produtos naturais e feiras orgânicas. Entretanto, são os supermercados que ganham destaque, pela busca da variedade e qualidade dos alimentos, visto que estes estabelecimentos representam uma atuação maior no cotidiano dos consumidores. Na cidade de Natal, o consumo de alimentos ou produtos orgânicos tem crescido no curso dos últimos anos, no entanto não se encontra estudos sobre o referido tema nesta localidade.

Diante do exposto sentiu-se a necessidade de conhecer o mercado consumidor de orgânicos realizando-se uma pesquisa com os consumidores em supermercados da cidade de NatalRN em fevereiro de 2006.

\section{REVISÃO DA LITERATURA}

\subsection{Expansão do Mercado de Orgânicos}

Como reflexo dos impactos causados pela agricultura convencional - degradação do meio ambiente, redução de mão-de-obra e de subsídios estatais - os alimentos orgânicos vêm ganhando espaço e conquistando um mercado exigente. A agricultura orgânica é uma alternativa para o agricultor, com uma produção barata e de alta qualidade, usando apenas insumos produzidos na própria lavoura.

Os consumidores passam a adquirir os orgânicos a fim de terem uma melhor qualidade de vida, prevenindo contra certos tipos de doenças causadas pelo excesso de agrotóxicos no organismo.

Em consonância com Muniz et. al. (2003, p. 315), 
Existe uma rede de interações envolvendo médicos, nutricionistas, educadores físicos, ambientalistas etc., que são indutores da formação e consolidação dos novos hábitos de consumo, e isso influencia diretamente o dimensionamento e a dinâmica do mercado dos produtos orgânicos.

A qualidade dos produtos orgânicos não está ligada apenas à preocupação com saúde humana, mas à valorização do agricultor, associação deste com a natureza, fundamentada por meio da preservação dos recursos naturais e de formas naturais de apropriação deste recurso.

O crescimento da produção orgânica e do mercado consumidor ocorre em todo o mundo. Os maiores mercados estão situados na Europa e nos Estados Unidos, que representam mais de 90\% das receitas auferidas nesse setor (Dulley, 2005).

Ormond et. al. (2002) refere-se a alguns dados do Centro Internacional de Comércio (ITC) de 1997, em que a Europa era o maior mercado consumidor mundial, com movimento anual de US\$ 6,2 bilhões, seguida pelos Estados Unidos (US\$ 4,2 bilhões) e pelo Japão (US\$ 1,2 bilhão).

Em 2004 nos Estados Unidos, os orgânicos já movimentavam 12 bilhões de dólares, o que equivale a $3 \%$ do faturamento da indústria de alimentos. Nos últimos cinco anos, a produção de alimentos orgânicos no Brasil passou de 40.000 para 300.000 toneladas, e o faturamento desses produtos passou de 50 milhões de dólares para 300 milhões de dólares, representando $0,5 \%$ do faturamento da indústria de alimentos no país (Veja, 2005).

O Brasil ocupa atualmente a segunda posição na América Latina em termos de área manejada organicamente, perdendo apenas para a Argentina. Os estados onde concentram 70\% da produção brasileira são: Paraná, São Paulo, Rio Grande do Sul, Minas gerais e Espírito Santo. No país, a produção visa o abastecimento do mercado interno, principalmente com legumes e verduras, utilizando diferentes canais de comercialização (feiras, hospitais, cestas a domicílio, lojas de produtos naturais, supermercados).

De acordo com Darolt (2002), pelo menos 30 tipos de produtos orgânicos vêm sendo produzidos no país, sendo que os principais produtos brasileiros exportados são café (Minas Gerais); cacau (Bahia); soja, açúcar mascavo, erva-mate, café, hortaliças, banana (Paraná); suco de laranja, açúcar mascavo e cristal, frutas secas e hortaliças (São Paulo); castanha de caju, óleo dendê e frutas tropicais (Nordeste); óleo de palma e palmito (Pará); guaraná (Amazônia); arroz, soja e frutas cítricas (Rio Grande do Sul) e hortaliças, banana, maçã, kiwi, arroz (Santa Catarina). Entre os produtos orgânicos processados, podemos destacar o mel (Minas Gerais, Amazônia); compotas de frutas, café solúvel, torrado e moído (Minas Gerais, São Paulo); castanha de caju e acerola (Ceará); hortaliças processadas (Rio de Janeiro, São Paulo, Paraná, Santa Catarina e Rio Grande do Sul); arroz (Rio Grande do Sul, Santa Catarina); suco de laranja concentrado e extratos vegetais secos (São Paulo); barra de cereais e açúcar mascavo (Paraná) e guaraná em pó (Amazônia). Os produtos de origem animal ainda estão sendo pouco explorados por problemas de falta de matéria prima orgânica e legislação inadequada. 
O mercado de produtos orgânicos além de ser um mercado de crescimento recente também trabalha com preços superiores aos dos alimentos convencionais. Para Schmidt (2001) apud Azevedo (2006), o preço justo que o alimento orgânico merece, deve ser compreendido da ótica dos benefícios ambientais e sociais que ele gera.

Visto o aumento de produção e de consumo de alimentos orgânicos, a importância da compreensão da organização do mercado destes produtos está além dos princípios naturais, principalmente se os produtores optam pela possibilidade de sucesso no ambiente econômico sob os princípios sustentabilidade.

Com base em uma pesquisa quantitativa de marketing, realizada por Monteiro et. al. (2004), verificou-se que o mercado dos orgânicos é atraente tanto para os produtores, como para os varejistas, o que leva a entrada de novos concorrentes. Esta situação nos leva a crer que é um mercado de lucros "passageiros”, pois com a maior oferta, provavelmente estas margens diminuirão e estes produtos deverão se tornar mais acessíveis. Mas, os orgânicos ainda têm uma baixa demanda quando comparados com os alimentos convencionais fazendo deles não competitivo o suficiente no mercado.

\subsection{Mercado dos orgânicos no Rio Grande do Norte}

No estado do Rio Grande do Norte já existem algumas empresas e agricultores que estão produzindo alimentos e produtos de origem orgânica, contudo o mercado ainda se encontra muito restrito.

A fazenda de camarão, Primar, localizada em Tibau do Sul (RN), está certificada pelo Institudo Biodinâmico (IBD) como aqüicultura orgânica, como também a empresa que industrializa seu camarão. Inicialmente produzindo apenas para o mercado interno, mas depois da BioFach 2005, houve uma proposta em trabalhar com carcinicultores na perspectiva de formar um consórcio de exportação, estimulando a substituição da criação tradicional pelo produto ecologicamente correto.

Outro produto certificado para o mercado externo é a amêndoa de castanha-de-caju orgânica, produzida por unidades de produção familiares, na Serra do Mel (RN), que estão inseridas na Coopercaju - Cooperativa dos Beneficiadores Artesanais de Castanha-deCaju.

De acordo com o site www.planetaorganico.com.br, no Rio Grande do Norte, além da Primar, produtora de ostras e camarões, outras empresas certificadas são, a Hortaviva Ltda (hortaliças), e a Sociedade para o Incentivo ao Pequeno Artesão do RN - SIPARN (frutas), todas elas certificadas pelo IBD.

\subsection{Produtos Certificados: Credibilidade dos Orgânicos}

A certificação dos alimentos orgânicos é uma forma de assegurar ao consumidor que o produto que ele está comprando foi produzido dentro de um processo orgânico, sem a utilização de agrotóxicos, respeitando o ambiente e o homem, etc. Se as informações contidas nos rótulos fossem totalmente fidedignas e os consumidores confiassem nessas informações, a certificação seria dispensável, porém, isso não acontece. 
Em consonância com Penteado (2003, p.48), “a certificação é um processo que atesta que determinado alimento é realmente orgânico e que o produtor está cumprindo com as normas vigentes para a produção orgânica”.

Para Darolt (2005, p.4),

A certificação é um processo de inspeção das propriedades agrícolas, realizado com uma periodicidade que varia de dois a seis meses, para verificar se o alimento orgânico está sendo cultivado e processado de acordo com as normas de produção orgânicas. O foco da inspeção não é o produto, mas a terra e o processo de produção. Assim, uma vez credenciada, a propriedade pode gerar vários produtos certificados, que irão receber um selo de qualidade.

O crescimento da demanda, criando preços diferenciados para os produtos, e o aumento do mercado, criando a impessoalidade nas relações entre produtor e consumidor, exigiram novos mecanismos de garantia de qualidade (Feiden et. al., 2002). Esta é assegurada pela existência de um Selo Oficial de Garantia fornecido pelas associações de agricultura orgânica e de um sistema de certificação de agricultores e firmas, acompanhado de assessoramento técnico e controle fiscalizador, envolvendo todos os atores - produtor, industrial e comerciante (Paschoal, 1994 apud Darolt, 2000).

Os movimentos de certificação para diferenciar produtos e produtores agrícolas são originários de países ricos, com setor agrícola forte e grupos sociais organizados, sendo a Europa o continente cujas principais iniciativas surgiram e se desenvolveram. O primeiro e mais importante organismo mundial desse movimento é a IFOAM, que elabora as normas básicas para a agricultura orgânica, a serem seguidas por todas as associações filiadas mundialmente (Nava, 2004).

As primeiras iniciativas de produção e comercialização de produtos orgânicos no Brasil foram estabelecidas por cooperativas de consumidores (Coonatura, no Rio de Janeiro, e Coolméia, no Rio Grande do Sul), no ano de 1978, aproximando consumidores e produtores (Fonseca, 2001).

Embora a certificação para os produtos orgânicos do Brasil tenha surgido tardiamente, esse processo tende cada vez mais a ser estendido para todo o setor agrícola, tendo em vista as crescentes medidas por parte dos países importadores. A primeira obra dedicada exclusivamente à produção de orgânicos foi elaborada em 1999, com o enrijecimento das legislações sobre sanidade, como a Lei do Bioterrorismo norte-americana (Dulley, 2004).

No Brasil a Instrução Normativa $\mathrm{n}^{0}$ 007/99 apresenta normas disciplinadoras para a produção, tipificação, processamento, envase, distribuição, identificação e certificação da qualidade de produtos orgânicos, sejam de origem animal ou vegetal.

O processo de certificação pode variar de 1 a 4 anos, dependendo do sistema de produção e do mercado consumidor. Para a exportação os produtos devem estar coerentes com a legislação do país de destino, pois os aspectos que caracterizam o produto como orgânico não são iguais para todos os países.

Em 2001, no Brasil existiam 275.576 hectares certificados. Em 2003, existiam mais de 800.000. Existe também uma quantidade enorme na produção de orgânicos especialmente 
nos estados do Rio Grande do Sul, Paraná e São Paulo, formalmente certificados ou não certificados. O número calculado de produtores orgânicos é ao redor 14.000 (Willer e Yussefi, 2004).

O presidente da IFOAM, Gunnar Rundgren, na BioFach/ Brasil, realizada em setembro de 2003, afirmou que a produção brasileira é importante tanto para a exportação quanto para o mercado doméstico. Ressaltou que o setor agrícola orgânico se desenvolveu no mundo mais rápido do que está proposto pela Agenda 21 para agricultura sustentável, e ainda estima que existam cerca de 25 milhões de hectares de produção orgânica que não fazem parte do mercado certificado (Dulley, 2003).

Para a certificação algumas etapas devem ser seguidas:

- Filiação a um órgão certificador - deverá ser efetuada através do preenchimento da proposta de sócio ou inscrição;

- Visita de inspeção - deverá ser feita por um técnico da entidade na propriedade agrícola, preenchendo relatório ou questionário.

- Análise do questionário da inspeção - deverá ser feita pela Comissão Técnica Certificadora.

- Transição - é o período de conversão para a agricultura orgânica determinado pela certificadora, de 12 a 18 meses.

- Aprovação (credenciamento) - é o contrato com o órgão certificador e a cessão dos selos.

- Inspeções - deverão ser semestrais ou anuais, pelos técnicos da certificadora.

\subsubsection{Instituições responsáveis pela certificação}

As instituições certificadoras definem o processo de certificação de acordo com as características da região em que atuam, podendo ser agregados requerimentos específicos sempre que considerem as exigências legais (Trivellato e Freitas, 2003).

O produto orgânico, ao trazer este nome na embalagem juntamente com o selo de uma Instituição Certificadora, mostra ao consumidor muito mais que um alimento isento de substâncias nocivas à saúde, mas de quem se adquire aquele produto. Ao ser gerado dentro de um sistema produtivo que preservou o ambiente natural, o produto orgânico contribui para a melhor qualidade de vida não de um consumidor isolado, mas de toda a sociedade.

No Brasil, a rotulagem ambiental pode ser feita por vários órgãos e associações reconhecidos, como as ONGs (Organizações Não Governamentais) e a ABNT (Associação Brasileira de Normas Técnicas).

Através das instituições certificadoras se verifica a qualidade e a origem de cada produto. Na figura 02 estão os principais selos de certificação, que garantem ao consumidor a certeza de estar levando para casa produtos orgânicos. 


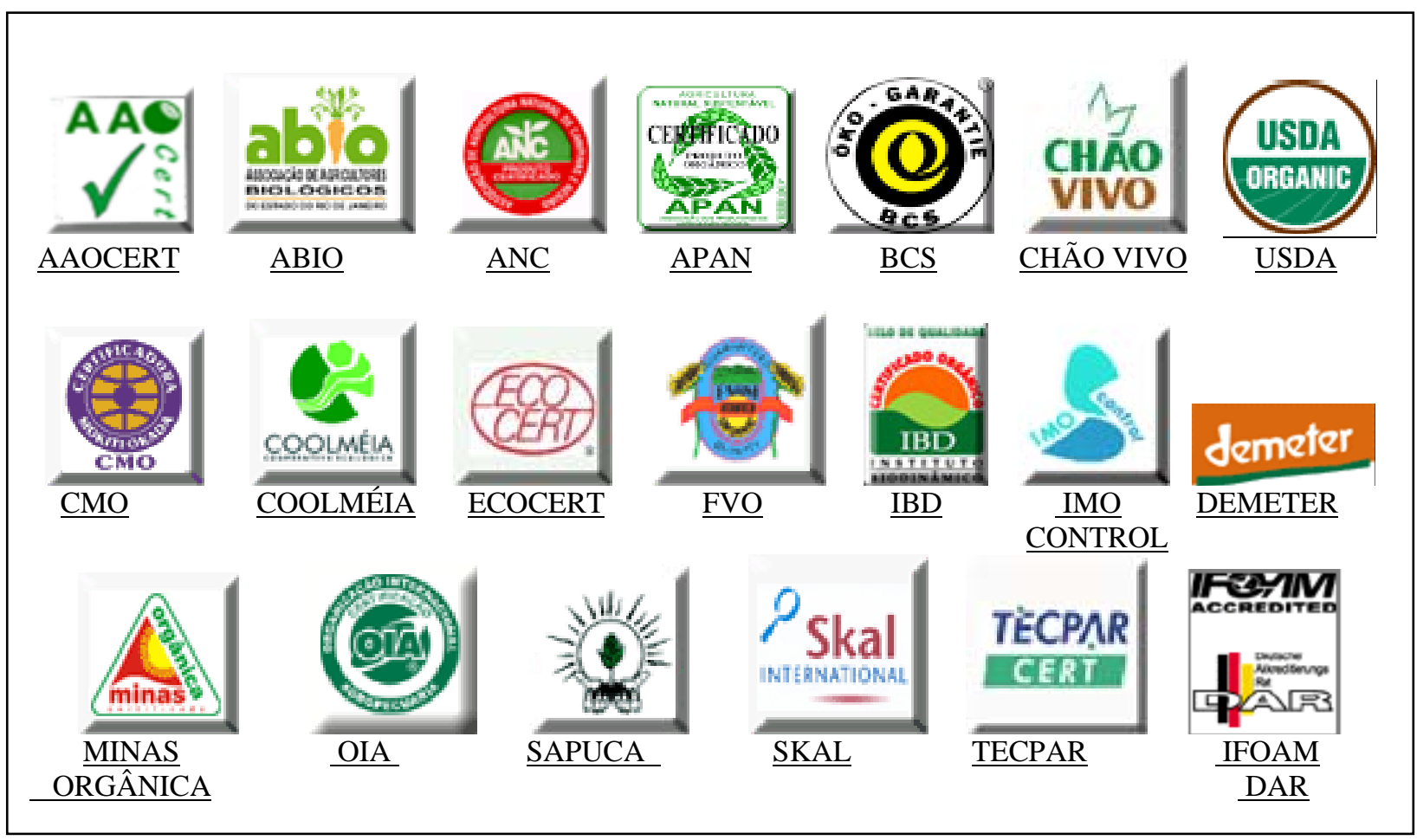

\section{METODOLOGIA}

\subsection{Amostragem}

A pesquisa foi realizada em supermercados da cidade de Natal-RN, onde existe uma população representativa circulante e que os consumidores pudessem encontrar com maior facilidade produtos de origem orgânica. Através de uma listagem dos supermercados (37) foram sorteados 6 distribuídos nas zonas: Norte Sul, Leste e Oeste. A amostra foi determinada pelo tempo de permanência no local da execução da pesquisa, compreendendo 131 entrevistados.

A coleta de dados foi realizada através de entrevista e aplicação de questionários com consumidores nos 6 supermercados escolhidos, no mês de fevereiro de 2006. E a apuração dos dados foi realizada através de planilhas eletrônicas com tabulação simples de todas as questões, no programa estatístico SPSS 13.0. As variáveis foram cruzadas a fim de estabelecer o perfil do consumidor orgânico.

A análise dos dados foi realizada objetivando organizar os dados apresentados, através do cruzamento de informações, de forma a fornecer as respostas à pergunta de pesquisa proposta pela investigação. Para isso, foram elaborados gráficos no programa Excel. Após, segue a interpretação, que consiste, fundamentalmente, em estabelecer a ligação entre os resultados obtidos com os conhecimentos quer sejam derivados de teorias revisadas neste trabalho, quer sejam de estudos realizados anteriormente sobre a temática. 


\section{RESULTADOS E DISCUSSÃO}

Em uma breve análise dos resultados, a maioria dos entrevistados da pesquisa era do gênero feminino (73\%), e apenas $27 \%$ do gênero masculino. As mulheres têm uma maior preocupação com uma alimentação saudável, por serem, na maioria das vezes, as responsáveis pela alimentação doméstica, e por apresentarem atenção redobrada à saúde devido o surgimento de doenças que aparecem com a idade. A faixa etária predominante foi acima de 50 anos, sendo que $35,1 \%$ tinham completado o $2^{\circ}$ grau o que representa a maioria dos entrevistados.

Ao examinar os dados coletados, foi possível verificar que 53\% dos entrevistados revelaram ter o costume de adquirir alimentos orgânicos, e que a minoria $47 \%$ não consumiam tais alimentos.

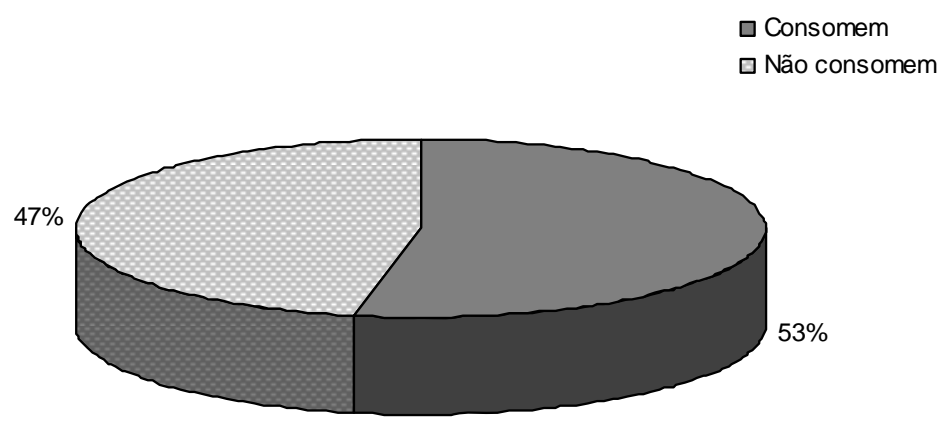

Gráfico 01- Distribuição dos consumidores de alimentos orgânicos em supermercados na cidade de Natal- RN, 2006.

Os resultados de um estudo realizado em Curitiba por Darolt (2000) apontam que o consumidor orgânico é normalmente um profissional liberal, a maioria (66\%) do gênero feminino, com idade variando entre 31 e 50 anos em $62 \%$ dos casos.

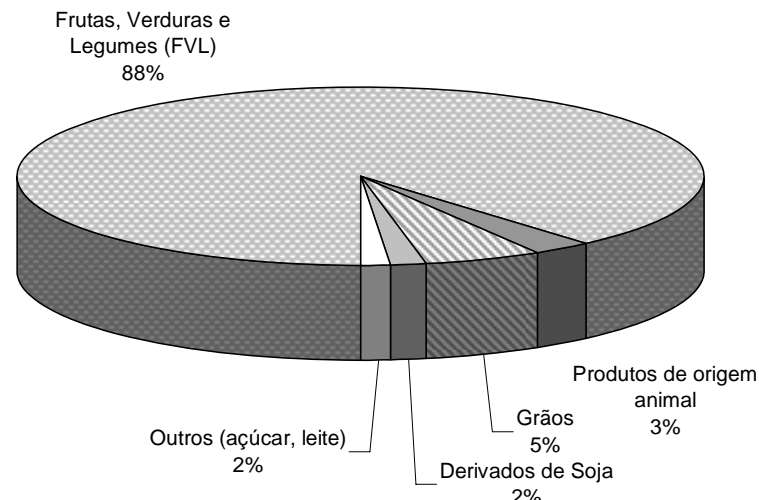

Gráfico 02 - Distribuição dos consumidores entrevistados em supermercados na cidade de Natal-RN 2006, de acordo com a preferência dos alimentos orgânicos. 
Constatou-se que por serem mais conhecidos pelos entrevistados e fornecidos pelos supermercados, as frutas, verduras e legumes (FVLs) são mais consumidas pelos entrevistados (88\%), seguidas dos grãos $(5,0 \%)$, pela maior variedade nas prateleiras, como arroz, feijão, café, soja, etc.. Poucos são os alimentos de origem animal como carnes $(3,0 \%)$ que se encontram nesses estabelecimentos, ou se existe não há divulgação.

De acordo com uma pesquisa realizada pela Secretaria de Infra-Estrutura Hídrica do Ministério da Integração Nacional, publicada na Revista Frutifatos (out., 2003), foi constatado que o consumo de frutas, legumes e verduras, é motivado fundamentalmente pelo valor nutricional que agrega à alimentação, promovendo um melhor estado de saúde para seus consumidores.

No gráfico 03, verifica-se que na zona Sul 30\% dos consumidores de alimentos orgânicos referiram sempre encontrar o produto no estabelecimento, valor superior à zona Leste com $18,6 \%$, Norte $(5,7 \%)$ e Oeste $(4,3 \%)$. Dos entrevistados que afirmaram encontrar "às vezes" os alimentos orgânicos, houve prevalência naqueles residentes na zona Leste (21,4\%), em segundo lugar com $8,6 \%$ os moradores da zona Sul, e com $4,3 \%$ os da zona Norte e Oeste. Apenas nestas duas últimas os entrevistados afirmaram nunca encontrar o produto orgânico, equivalendo a 1,4\% nestas duas localidades, ficando evidente que os mesmos apresentam deficiência na oferta de orgânicos.

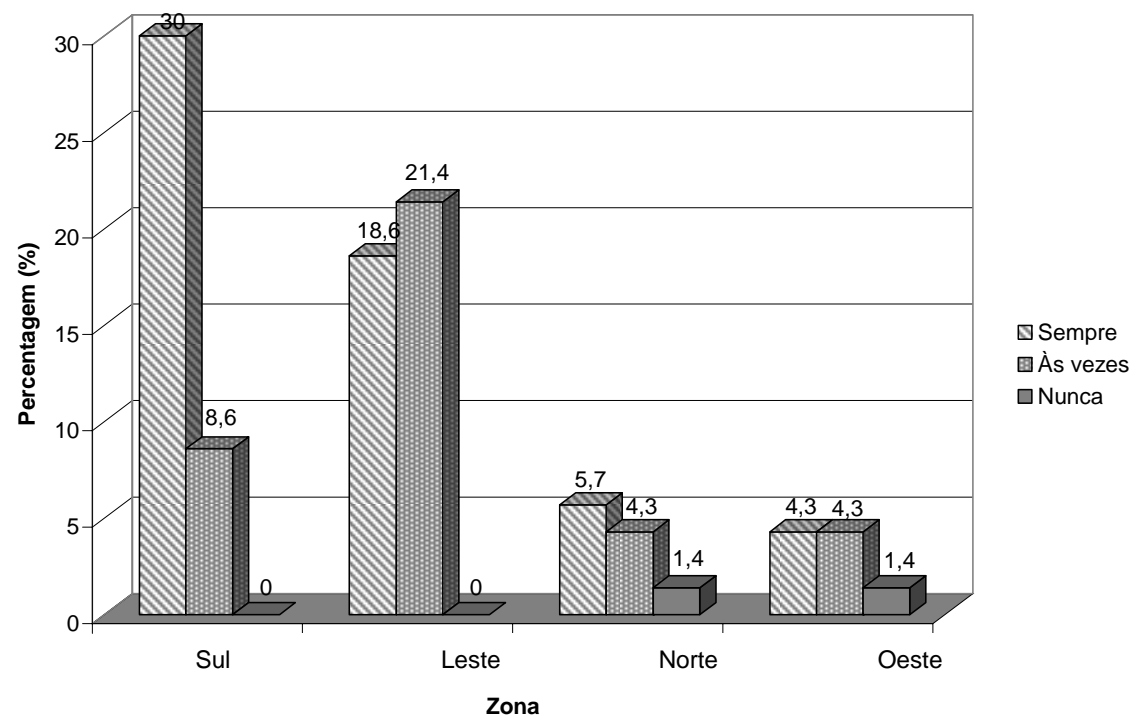

\section{Gráfico 03 - Distribuição dos consumidores entrevistados em supermercados na cidade de Natal-RN 2006, de acordo com a zona em que moram $x$ freqüência que encontram o alimento orgânico no estabelecimento.}

De acordo com Souza e Mata (2005), existem discussões geradas em torno do papel do marketing ecológico para os produtos orgânicos, voltados à conservação ambiental. Estas aparecem em duas perspectivas: em uma delas, autores o consideram como um benefício, por estar ligado à conscientização da sociedade para com problemas ambientais; na outra, autores consideram-no como maléfico, por banalizar, muitas vezes, os problemas ambientais no sentido de se aproveitar do atributo para almejar ganhos financeiros.

O gráfico 04 identifica os motivos que levaram os consumidores a não adquirir o produto orgânico. 


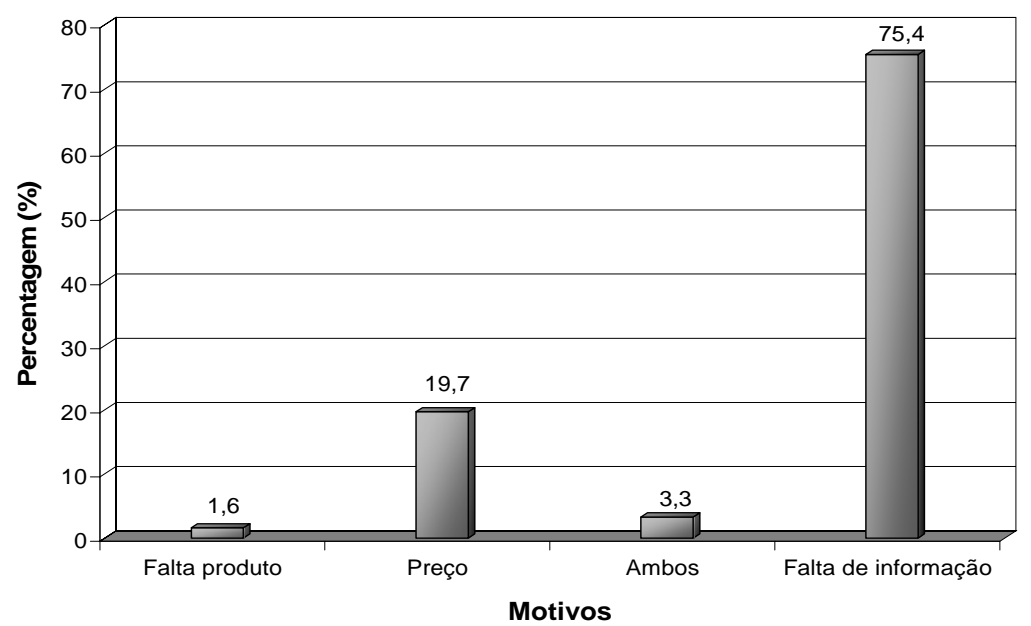

\section{Gráfico 04 - Distribuição dos consumidores entrevistados em supermercados na cidade de Natal-RN 2006, de acordo com os fatores que levam ao não consumo dos orgânicos.}

De acordo com os entrevistados que não optam pelos orgânicos o fator preponderante se enquadra na falta de informação do consumidor e/ ou do estabelecimento sobre a oferta desses alimentos, representando 75,4\% dos consumidores, um número bem relevante. Quanto à desinformação pessoal enquadram-se, principalmente, aqueles com nível de instrução baixo. O outro fator diz respeito ao pouco investimento dos supermercados em divulgação de seus produtos orgânicos no próprio estabelecimento. No entanto, contrário a estes, existem supermercados em Natal, na zona Sul, que investem seguramente na demanda dos orgânicos, informando com cartazes e placas sobre onde estes alimentos estão localizados nos estabelecimentos. Muitos dos alimentos industrializados são organizados juntamente com os produtos naturais e os dietéticos, o que de certa forma atrapalha a visualização do produto quando não informado pelo estabelecimento.

Com 19,4\% alguns entrevistados responderam não consumir os orgânicos pelo preço ser mais alto que o do convencional. Para Trivellato e Freitas (2003), como o produto orgânico tem um custo mais elevado que o convencional constitui-se um produto elitista.

Para os que relacionaram a não aquisição do orgânico à falta do produto (1,6\%), diz respeito à baixa demanda nos supermercados, oferecendo poucas opções para os consumidores. Apenas 3,3\% adquiriam esses produtos pela falta do produto ou pelo preço pouco acessível.

\section{CONCLUSÃO}

Diante do exposto verifica-se que consumo de alimentos orgânicos já é uma realidade na maioria das cidades brasileiras, inclusive na capital potiguar. Os supermercados se abastecem destes produtos a fim de atender a demanda dos consumidores, mostrando, com isso, ótimos concorrentes das lojas especializadas e feiras livres. 
De acordo com a pesquisa realizada com os consumidores que freqüentam supermercados na cidade de Natal, foi identificado o consumo de alimentos orgânicos por 53\% dos entrevistados, a maioria do gênero feminino, acima de 50 anos.

O grupo de alimentos mais consumidos foi o de FLV's - frutas, verduras e legumes representando $88 \%$ da preferência dos entrevistados, por serem de mais fácil acesso e a oferta ser maior.

O consumo dos orgânicos está diretamente ligado à questão de moradia, uma vez que o poder aquisitivo nas zonas Sul e Leste são melhores do que nas zonas Oeste e Norte. Os supermercados dessas localidades também são os maiores investidores na oferta dos orgânicos, os quais investem na divulgação dos alimentos orgânicos.

Apesar do mercado de orgânicos ter se destacado recentemente, ainda se encontra dificuldade em encontrar certos alimentos. No entanto, o fato de $47 \%$ dos entrevistados não consumirem alimentos orgânicos, está ligado, principalmente, à falta divulgação destes pelo estabelecimento. Outro fator a considerar é sem dúvida o preço, que é bem elevado quando comparado com os alimentos convencionais.

É importante ressaltar que o alimento orgânico é muito mais do que um produto sem agrotóxico. É, sem dúvida, o resultado de um sistema de produção agrícola que busca manejar de forma equilibrada o solo e demais recursos naturais conservando-os em longo prazo e mantendo a harmonia desses elementos entre si e com os seres humanos, em prol da sustentabilidade.

\section{REFERÊNCIAS BIBLIOGRÁFICAS}

Azevedo, Elaine de. Alimentos Orgânicos: ampliando os conceitos de saúde humana, ambiental e social. 2 ed. Tubarão: Unisul, 2006. 267p.

Brasil. Instrução Normativa N. 007 de 17 de maio de 1999. Estabelece normas para produção de produtos orgânicos vegetais e animais. Diário Oficial da União, Brasília, n.94, Seção 1, p. 11-19. mai. 1999.

Darolt, M.R. As Dimensões da Sustentabilidade: Um estudo da agricultura orgânica na região metropolitana de Curitiba-PR. Tese (Doutorado em Meio Ambiente e Desenvolvimento). Universidade Federal do Paraná. Curitiba, 2000. 310 p.

Darolt, M.R Agricultura Orgânica: inventando o futuro. Londrina: IAPAR, 2002. v. 1. $250 \mathrm{p}$.

Darolt, M.R. Comparação entre a qualidade do alimento orgânico e a do convencional. In: Strigheta, P.C; Muniz, J.N. Alimentos Orgânicos: Produção, tecnologia e Certificação. Viçosa: UFV, 2003. cap. 7. p.289-312.

Darolt, M.R. Alimentos Orgânicos: Um Guia para o Consumidor Consciente. IAPAR/ ACOPA. 2 ed. Curitiba, 2005.

Dulley, Richard Domingues. Produtos Agrícolas Orgânicos: Brasil sobe para a quinta posição em extensão de área. Instituto de Economia Agrícola. 2005. 
Dulley, Richard Domingues. Certificação Orgânica: A importância da documentação. Instituto de Economia Agrícola. 2004.

Ormond, J.G.P. et. al.. Agricultura Orgânica: Quando o passado é futuro. BNDES Setorial. Rio de Janeiro, n. 15, p. 3-34, mar. 2002.

Feiden, Alberto et. al.. Processo de conversão de sistemas de produção convencionais para sistemas de produção orgânicos. Cadernos de Ciência \& Tecnologia, Brasília, v.19, n.2, p.179-204, maio/ ago. 2002.

Fonseca, Maria Fernanda de Albuquerque Costa e. A certificação de alimentos orgânicos no Brasil. Niterói, 2001.

Muniz, José Noberto et. al.. Mercado de produtos orgânicos: além do natural. In: Strigheta, P.C; Muniz, J.N. Alimentos Orgânicos: Produção, tecnologia e Certificação. Viçosa: UFV, 2003. cap.8. p. 313-330.

Monteiro, Marcelo Nogueira de Castro et. al.. Os alimentos orgânicos e a percepção de seus atributos por parte dos consumidores. VII SEMEAD. São Paulo, 2004.

Orgânicos, quem são mesmo? Frutifatos, Brasília, n. 4, p. 38-40, out. 2003.

Penteado, Sílvio Roberto. Introdução à agricultura orgânica. Viçosa: Aprenda Fácil, 2003. $240 \mathrm{p}$.

Nava, Evandro Jackson Redivo. Estratégias de marketing junto ao mercado de consumo, para aquisição de alimentos orgânicos: Uma abordagem do mix de marketing. Florianópolis, UFSC, 2004. Programa de Pós-Graduação em Engenharia de Produção. 167 p.

Souza, Aline Conceição e Mata, Henrique Tomé da Costa. Análise do comportamento do consumidor de produtos orgânicos nos municípios de Ilhéus e Itabuna, Bahia. I Encontro de economia baiana. Salvador, 2005. Disponível em: $<$ http://www.mesteco.ufba.br/scripts/encontro2006/pdf/artigo/08.pdf $>$. Acesso em: 25 jun. 2006.

Willer, H. e Yussedi, M. Organic agriculture worldwide: statistics and future prospects. feb. 2004. Disponível em: <http://www.ifoam.org>. Acesso em: 26 abr. 2006.

Zakabi, Rosana. A mania dos orgânicos. Revista Veja. Ano 38, n. 47, p.82-84, 2005. 